\title{
Experimental study of flow characteristics around floodplain single groyne
}

\author{
Mona M. Mostafa ${ }^{\mathrm{a}, \mathrm{b}^{*}}$, Hassan S. Ahmed ${ }^{\mathrm{a}, \mathrm{c}}$, Ashraf A. Ahmed ${ }^{\mathrm{d}}$, Gamal A. Abdel-Raheem ${ }^{\mathrm{e}}$, and Nashat A. Ali ${ }^{\mathrm{e}}$ \\ ${ }^{a}$ Dept. of Civil Engineering, Faculty of Engineering, South Valley University, Qena, 83523, Egypt. \\ ${ }^{b}$ Dept. of Civil Engineering, Nagoya Institute of Technology, Nagoya 466-8555, Japan; E-mail: Mona.Mahmoud@eng.svu.edu.eg \\ ${ }^{c}$ Faculty of Engineering at Rabigh, King Abdul-Aziz University, Kingdom of Saudi Arabia; E-mail: \\ Hassan_safi74@eng.svu.edu.eg \\ ${ }^{d}$ Dept. of Civil and Environmental Engineering, Brunel University London, Kingston Lane, Uxbridge UB83PH, UK; E-mail: \\ Ashraf.Ahmed@brunel.ac.uk \\ ${ }^{e}$ Dept. of Civil Engineering, Faculty of Engineering, Assiut University, Assiut, Egypt.
}

\section{Abstract}

This study investigated the flow around river's floodplain single groynes. Two different compound channels with one and two symmetrical floodplains having widths of 1- and 2-times of the main channel width, respectively, were used. Both impermeable and permeable groynes with three different relative lengths (relative to the floodplain width) and having three different permeability values of 40,60 , and $80 \%$ were investigated. The $3 \mathrm{D}$ flow velocities were measured in the horizontal plane at 0.25 and 0.5 of floodplain water depth $\left(\mathrm{h}_{\mathrm{f}}\right)$, and in the vertical plane at the main channel's centerline. Therefore, the flow velocities in the longitudinal, lateral, and vertical directions, and the flow water surfaces were measured and analyzed. The results showed that, as the groyne permeability increased up to $60 \%$, a reduction of up to $30 \%$ to the maximum velocity and $22 \%$ to the tip velocity were observed. The permeable groyne length had limited influence on the flow structure. Both the groyne permeability and the length ratio had significant effects on the floodplain water depth. The scouring and the deposition activities resulting from impermeable groynes can be avoided, should the groyne length be kept below half of the floodplain width.

Keywords: Compound channel; Flow pattern; Groyne permeability; Groyne relative length; water surface.

\footnotetext{
* Corresponding author. Dept. of Civil Engineering, Faculty of Engineering, South Valley University, Qena, 83523, Egypt.. E-mail address: Mona.Mahmoud@eng.svu.edu.eg (Mona Mostafa).
} 


\section{Introduction}

Groynes are hydraulic structures used to protect banks from erosion and maintain the stream water level. They can also be used for controlling the flow for navigation safety, improving the channel alignment, and trapping littoral drift or retard erosion of the banks and shores. The groyne field is very beneficial to river ecosystem. Groynes can be either permeable or impermeable. The impermeable groynes are generally constructed using local rocks, gravel, or gabions while the permeable ones consist of rows of piles, bamboo, or timbers. Groynes may be built as a single structure, namely a single groyne, or as a series of groynes built in a row along one or both sides of a river (Ahmed et al., 2010; Alauddin et al., 2011; Alvarez, 1989; Ettema and Muste, 2004; Gu and Ikeda, 2008; Muraoka et al., 2008; Uijttewaal, 2005; Teraguchi et al., 2008; Yeo et al., 2005). Of interest in the design of groynes, is the disturbance the structure causes to the flow. Within the vicinity of these structures, a complex three-dimensional, highly turbulent flow field is generated. They induce adverse pressure gradients which separate the approach flow and consequently the so-called horseshoe vortices (HVs) are formed (Constantinescu et al., 2009;

Koken, 2011; Koken and Constantinescu, 2008). The construction of groynes has a considerable effect on upstream water levels. In spite of their impact during the flood stages, the backwater effect due to groynes is usually neglected in their design (Soliman et al., 1997). It is therefore necessary to find out how far of the downstream of such structures the disturbance extends (Francis et al., 1968; Koken, 2011).

Various experimental and numerical studies were conducted to investigate the influences of different structures such as groynes, on the flow characteristics and patterns in their vicinity in open channels (e.g. Alauddin et al., 2011; Alvarez, 1989; Constantinescu et al., 2009; Ettema and 
Muste, 2004; Francis et al., 1968; Gu and Ikeda, 2008; Koken, 2011; Ahmed, 2011,2013; Koken and Constantinescu, 2008; Liu et al., 1994; McCoy et al., 2008; McCoy et al., 2007, 2006a, 2006b; Muraoka et al., 2008; Rebhock, 1929; Teraguchi et al., 2008; Uijttewaal, 2005, 1999; Uijttewaal et al., 2001; Yeo et al., 2005). In order to better understand the effect of groynes installation on the flow, an accurate description of the flow characteristics in compound channel without groyne is needed. A significant momentum exchange between the main channel and floodplains occurs, causing flow deceleration in the main channel and acceleration on the floodplains. It is postulated that large-scale plan-form vortices, rotating about a vertical axis and stream wise secondary flows are the reason for the main momentum exchange/transfer between the main channel and the floodplain (Ali et al., 2007; Ali and Mohamed, 1991; Prooijen et al., 2005; Tominaga et al., 1997; Tominaga and Nezu, 1991).

Koken (2011) investigated experimentally and numerically the turbulent flow structure around an isolated spur dike with semi-circular end on rectangular flume at three different approach flow angles. The spur dike length and width relative to the flume width were 0.233 and 0.067, respectively. Both the size and the orientation of the horseshoe vortex system changed considerably with the approach flow angle. The main necklace vortex was largest in size and most coherent for the approach flow angle $90^{\circ}$, and within this orientation, it had larger amplitude bimodal oscillations compared to the $60^{\circ}$ and $120^{\circ}$ orientation cases. Jong and Tominaga (2008) measured the velocities in a compound open channel by setting groynes of different lengths on the floodplain. The floodplain groynes deflected the main flow and produced 3-D flow structures around them. These local flow features generated strong secondary flows in the main channel. The flow characteristics, the velocity distribution around single groyne in combination with 
the relative depth $H_{r}$ (the ratio of the water depth in the floodplain and main channel) and the longitudinal length of the recirculation zone were discussed (Baba et al., 2010; Peltier et al., 2009). The flow structure, velocity, and water depth mainly depend on the floodplain impermeable groyne relative length and the distance between the two series groynes (relative to the groyne length) (Ahmed et al., 2010).

The large-scale groyne system has been introduced and widely used in some rivers floodplains for various purposes such as flood attenuation, river banks protection and safety of downstream areas; especially, in rivers with large floodplains such as Japanese Rivers (e.g. Arakawa River). In some reaches of the Arakawa River, the floodplain width relative to the main river width is more than 10 (Ahmed et al., 2010, 2011).

Impermeable groynes, transverse levees, and bridge embankments are considered as contractions on the stream-wise flow direction. The flow structures around groynes on the floodplain are presumably different from those in a single main channel (Ahmed et al., 2011; Ahmed et al., 2010; Jong and Tominaga, 2008). The flow characteristics and patterns in the floodplain groynes vicinity and main channel vary according to groyne type and size. The flow through a permeable groyne penetrates the structure partly so that the downstream velocity is reduced. The permeable groyne resistance to the flow is less than that of the impermeable one. Nonetheless, the permeable groyne has the advantages of better stability and relatively easy maintenance. Therefore, analysis of groynes and their influences is necessary to select the appropriate groyne type in the field (Ahmed et al., 2010; Fukuoka et al., 2000; Gu et al., 2011; Gu and Ikeda, 2008; Jong and Tominaga, 2008; Kang et al., 2011; Yeo et al., 2005).

Going through the literature shows that the influences of the floodplain's width and groyne's 
type and length on the flow in the floodplain and main channel of natural and artificial rivers still need more quantitative and extensive analyses. Therefore, the main objectives of the present study are: (1) to investigate and verify the influences of large-scale floodplain single permeable and impermeable groyne on the flow structure, velocity, and water depth, and (2) to evaluate the advantages and disadvantages of using groynes on channels' floodplain as flood protection work.

To achieve these objectives, two compound channels with flat and fixed bed were used. The first one has two symmetrical floodplains with relative width $=2$, normalized to the width of the main channel and only impermeable groynes were used here. The second one consisted of the main channel and one floodplain with relative width=1, and both impermeable and permeable groynes (permeability $=40,60$, and $80 \%$ ) were tested in this case. In both cases, the relative lengths of the groyne models $L_{r}$ (where, $L_{r}=$ groyne length $L_{g} /$ floodplain width $b_{f}$ ) were $L_{r}=0.5$, 0.75 , and 1.0, respectively. The 3D flow velocities (in the longitudinal, lateral and vertical directions), and the water surface elevation were measured and analyzed in the horizontal plane (HP) at 0.25 and 0.5 of floodplain water depth $\left(h_{f}\right)$, and in the vertical plane (VP) at the main channel's centerline.

\section{Materials and methods}

A general functional relationship characterizing the flow structure around groynes in compound channel floodplains (Fig 1a) can be written among physical variables that include: floodplain width $b_{f}$, main channel width $b_{m}$, channel total width $B=\left(b_{f}+b_{m}\right)$, floodplain water depth $h_{f}$, floodplain bed height $z_{f}$, main channel water depth $H=z_{f}+h_{f}$, channel longitudinal slope $S_{o}$, longitudinal distance measured from the groyne centerline in the flow direction $X$, lateral distance measured from the right side wall of the main channel $Y$, vertical distance measured from 
main channel bed $Z$, groyne length $L_{g}$, permeability $P \%$ and its orientation angle to the channel main direction $\alpha$, flow discharge $Q$, approach velocity $U_{o}$ which is the counter approach velocity measured at the same streamline, local longitudinal velocity $U$, local lateral velocity $V$, local vertical velocity $W$, maximum velocity $U_{\max }$, minimum velocity $U_{\min }$, groyne tip velocity $U_{t i p}$, inclination angle of tip velocity to the horizontal direction $\theta$, and gravity acceleration $g$, density $\rho$ and kinematic viscosity $v$ ):

$$
\Phi\left(b_{f}, b_{m}, B, h_{f}, H, S_{o}, X, Y, Z, L_{g}, P, \alpha, Q, U_{o}, U, V, W, U_{\text {max }}, U_{\min }, U_{t i p}, \theta, g, \rho, v\right)=0
$$

Using the dimensional analysis Buckingham's " $\pi$ " theorem, in which $U_{o}, b_{f}$ and $\rho$ are selected as repeated variables representing the flow characteristics, channel geometrical characteristics and fluid parameters respectively, and considering such dimensionless parameters that have been fixed and are constant as $\left(B / b_{f}, b_{m} / b_{f}, h_{f} / b_{f}, H / b_{f}, S_{o}, \alpha, \theta\right.$, Reynold and Froude numbers), Eq. (1) can be reduced to:

$U^{*} / U_{o}=\Phi\left(X / b_{f}, Y / b_{f}, Z / h_{f}, L_{g} / b_{f}, P\right)$

In which, $U^{*}$ is a characteristic velocity $=\left(U, V, \mathrm{~W}\right.$, or $\left.U_{t i p}, U_{\max }, U_{\min }\right), X / b_{f}=X_{r}=$ Relative distance along the channel centerline, $Y / b_{f}=Y_{r}=$ Relative channel width, $Z / h_{f}=Z_{r}=$ Relative depth, and $L_{g} / b_{f}=L_{r}=$ groyne relative length .

Finally the relationship between the above mentioned parameters could be as:

$$
U^{*} / U_{o}=\Phi\left(X_{r}, Y_{r}, Z_{r}, L_{r}, P \%\right)
$$

In the case of the compound channel with only one floodplain, the flume was $0.30 \mathrm{~m}$ in both depth and width directions, and $13.5 \mathrm{~m}$ in length, which incorporates transparent test section of 10 $m$ length. The flume was adjusted to a longitudinal slope of 0.0025 . The rectangular flume section was converted into Perspex-Acrylic unsymmetrical compound channel section having a main 
channel width $b_{m}=0.15 \mathrm{~m}$ and one left side floodplain with the same width of main channel $b_{f}=$ $0.15 m$ (where $\left.b_{f} / b_{m}=1.0\right)$. The roughness coefficients of the main channel and the floodplain were kept constant and equal. A steady discharge $Q$ was regulated to be $17.50 \mathrm{l} / \mathrm{s}$ and the floodplain flow water depth $h=0.08 m(h / H=0.34)$. Reynolds number was always sufficiently high (from $6.1 \times 10^{4}$ to $9.2 \times 10^{4}$ ) to guarantee a fully turbulent flow whereas Froude number was kept constant at 0.30 .

The longitudinal velocity $U$, lateral velocity $V$, and vertical velocity $W$ of the steady flow were measured in both the HP, which was located at a depth of $0.25 h_{f}$ from the floodplain bed and in the VP at the main channel centerline. The flow velocities components in the HP and VP were measured at several locations at relative distances $X_{r}$ within the range from -7.5 to +17.5 using an Acoustic Doppler Velocimeter (16-MHz MicroADV, Sontek) with sampling frequency $20 \mathrm{~Hz}$ and duration time ranged from one to two minutes. At each measuring point, the mean velocities in longitudinal, transverse and vertical directions, $U, V$ and $W$ were obtained by averaging the velocities readings of the velocimeter due to the steady flow conditions. The water surface elevation was measured at several locations of the upstream and the downstream of the groyne by a point gauge with accuracy of $0.10 \mathrm{~mm}$ mounted on a movable sliding carriage. The experiments were conducted using groyne models with three different permeability values of 40, 60 , and $80 \%$, in addition to the case of impermeable groynes. The permeable groynes were made of glass piles with cross sectional diameter of $0.50 \mathrm{~cm}$, and the groyne relative lengths $L_{r}$ were 0.5 , 0.75, and 1.0 (Fig. 1b). All groynes were kept perpendicular to both the main channel centerline and the longitudinal flow direction. Other experiments are a part of a series of experiments that were conducted using models of straight impermeable groynes with the same $L_{r}=0.5,0.75$, and 
1.0 installed perpendicularly on one or two sides of symmetrical compound channel with two large floodplains (Table 1). The flume is $0.50 \mathrm{~m}$ in depth and width, and $15 \mathrm{~m}$ in length. The working section of the flume is the middle section with a length of $13 \mathrm{~m}$, starting from a point $1 \mathrm{~m}$ downstream of the inlet to a point $1 m$ upstream of the outlet. The cross-section of the flume was converted into a wooden symmetrical compound channel section consisting of main channel with width $B=0.1 \mathrm{~m}$ and two symmetrical floodplains with width $b=0.2 \mathrm{~m}$ (the floodplain relative width $\left.b_{f} / B=2\right)$. The main channel total water depth $H$ was $0.24 m$ while the floodplain water depth $h$ was $0.08 m(h / H=0.33)$. A steady flow with discharge $Q=15 l / s$ and Froude number of 0.26 were used. The flow velocities were measured by an electromagnetic velocity meter (type of main amplifier: VM-2000, type of sensor: VMT2-200-04P, KENEK Co., Ltd.). The sensor is 15.0 $\mathrm{mm}$ in length and $4.0 \mathrm{~mm}$ in diameter. The measurement point is located at the mid height of the sensor with $20.0 \mathrm{~s}$ and $50 \mathrm{~Hz}$ sampling frequencies. The flow velocities were measured at the horizontal plane HP at the floodplain mid water depth, and at the vertical plane VP at the main channel centerline (Ahmed et al., 2010).

\section{Results and discussion}

\subsection{Flow velocity profiles and patterns}

\subsubsection{Flow velocity profiles and patterns in the horizontal plane}

In the case of floodplain impermeable groyne at one side of symmetrical compound channel, the groyne relative length $L_{\mathrm{r}}$ significantly affected the flow velocity and water depth, downstream of the groyne, while at the upstream side, only little effects were noticed (Figs. 2 and 3). At the downstream side of the groyne, a recirculating flow region was generated. The centre of the eddy zone moved toward the groyne as $L_{\mathrm{r}}$ increased while the flow moved towards the main channel and the opposite floodplain. The relative longitudinal velocity $\left(U / U_{o}\right)$ on the opposite floodplain increased by 75,125 , and $175 \%$ for $L_{\mathrm{r}}=0.5,0.75$, and 1.0 , respectively and the location of the 
maximum value also existed there for $L_{\mathrm{r}}=0.75$ and 1.0 ; the corresponding location was in the region of the main channel for $L_{\mathrm{r}}=0.5$ (Figs 2 and 3). The value of the negative velocity downstream of the groyne was more than $55 \%$ of its original approach velocity value (this happened for $\left.L_{\mathrm{r}}=1.0\right)$.

Figure 4 shows the experimental results of two symmetrical single impermeable groynes installed in both floodplains of the symmetrical compound channel (i.e. arranged in one-line) with the same flow and channel properties. Increasing the relative length of the groyne reduced the downstream velocities of floodplains. Region of the negative velocities appeared downstream of the groynes, its magnitude reached the same value of the original approach velocity in the opposite direction of the flow or even more. For instance, the main channel downstream velocity was greater than $200 \%$ of its original approach velocity in case of $L_{r}=1.0$. Also in the floodplain area, the center of the negative velocity region moved upstream towards the groyne. Both the separation width and length upstream and downstream of the groynes increased as the cross-sectional area of the floodplain flow was reduced at the groyne. The average separation width and length were 0.4- and 8-times the groyne length, respectively. Most of the changes on the water depth occurred downstream of the groyne and they were within the distance of about 6 times the groyne length.

In the cases of single impermeable groyne in compound channel with one floodplain, the upstream flow was deviated by the groyne from the floodplain towards the main channel in the downward direction; this has greatly affected the main channel flow. As a consequence, the contraction caused by the groyne increased the velocity in the main channel at the groyne tip. A large recirculation vortex was formed downstream of the groyne with larger size for large $L_{r}$. A 
spiral vortex downstream of the groyne was created, due to the velocity difference between the main channel and the floodplain and because of the deviated flow at the floodplain bed toward the main channel (Fig. 5). The spiral vortex caused a strong transverse velocity from the main channel to the floodplain and an upward-flow at the interface zone. The spiral vortex may cause sediment transportation in the compound open channel.

The cases of floodplain permeable groynes in compound channel with one floodplain are presented in Figs. (6-8). For groynes having same permeability, as $L_{r}$ increased the velocity reduction in the floodplain zone extended in the two directions downstream of the groyne and towards the main channel. The longitudinal approach velocity upstream of the groyne was slightly affected by the groyne permeability $P$ and $L_{r}$. Also, the location where the velocity was reduced, moved towards the downstream and became closer to the groyne. Comparing the permeable groynes with the impermeable ones shows that, the permeable groynes caused a disappearance of the vortex downstream of the groynes. Also, the longitudinal velocity decreased in the floodplain zone and slightly increased in the main channel. The floodplain velocity was reduced as the groyne's permeability decreased. The flow velocity in the main channel was slightly affected as the groyne relative length decreased and its permeability increased.

The significant effect of the impermeable groynes in the one floodplain compound channel on the flow occurred at a relative distance $X_{r}$ from -2 to 14 . Beyond this range, the flow was slightly affected by the groynes installation (Figs. 5 and 7). The maximum relative velocity $\left(U / U_{o}\right)_{\max }$ has a direct relationship with $L_{r}$, while $\left(U / U_{o}\right)_{\min }$ was slightly affected. The $\left(U / U_{o}\right)_{\max }$ were $1.85,1.7$ and 1.5 for $L_{r}=1,0.75$ and 0.5 respectively (Fig. 7). In the case of impermeable groyne at one or two sides of symmetrical compound channel, the $\left(U / U_{o}\right)_{\max }$ were about $2.75,2.4$ 
and 1.75 for $L_{r}=1,0.75$ and 0.5 , respectively (Figs. 3 and 4). These changes in the maximum velocity values may be attributed to the difference in the floodplain relative width. The minimum relative velocity changed with the same rate for all cases of the impermeable groyne where its minimum value was -0.5 . In the case of impermeable groynes, a reverse flow occurred on the floodplain outer zone close to the bank, but it gradually disappeared.

With the permeability increase, values of $\left(U / U_{o}\right)_{\max }$ and $\left(U / U_{o}\right)_{\min }$ dropped down and the reverse flow downstream of the groynes disappeared (Fig. 7). The effect of the relative length of permeable groyne was smaller than that of impermeable groynes. In the case of permeable groynes, the maximum transverse velocity towards the main channel near the groyne tip was about 80,70 , and $50 \%$ of the floodplain approach velocity for $L_{r}=1,0.75$, and 0.5 respectively (Figs 7-9). For the cases with small permeability, the lateral velocity downstream of the groyne was mainly heading towards the main channel but its value was smaller compared with the impermeable cases. As $L_{r}$ decreased, the direction of the lateral flow downstream of the groyne was towards the floodplain. The spiral vortex, which was formed in the cases of impermeable groyne, disappeared and an upward flow with small values occurred at the interface between main channel and floodplain. This upward-flow is responsible for the generation of secondary flow in the compound channels. The secondary flow slightly reduced when the $L_{r}$ was small.

For all the cases, there was a downward flow occurred at the groyne tip. The lateral and down-flow velocities, upstream of the groyne tip, caused the well known horseshoe vortex (HVs), which is the reason for strong scour around the groyne (Ettema, 2004; Jong and Tominaga, 2008; Koken, 2011). This phenomenon occurred and formed for all cases but it dropped down as the groyne permeability increased (Fig. 9). 
Figure 10 shows the relationships between the ultimate maximum and minimum relative velocities and

both the groyne permeability $P$ and $L_{r}$ for the case of floodplain single groynes in compound channel with one

floodplain being compared with results of Kang (2011). The ultimate value is the absolute value of the

maximum and minimum relative velocity values of the measured cross sections (floodplain and main channel)

down and upstream of the groyne. Exponential empirical formulae describing those relationships were

suggested in Table 2 . The groyne relative length had no obvious effect on the relative minimum velocity value.

The average values of the relative minimum velocities were found to be $-0.5,0.4,0.6$ and 0.8 for groyne with permeability $P=0,40,60$ and $80 \%$, respectively. The influences of groyne permeability on the flow pattern over the floodplain area could be divided into two groups: the first one when, $0<P \leq 20 \%$ and the second one when, $20 \%<P \leq 80 \%$. In the low range of permeability when $0<P \leq 20 \%$, small vortexes were formed over the floodplain just downstream of the groyne. In the second range of $P>20 \%$, the vortex vanished and the minimum velocity was more than $25 \%$ of the approach velocity.

\subsubsection{Velocity profiles and flow pattern in the vertical plane.}

In most of the cases, the velocity $U$ in the main channel increased near the bed and reached a maximum value of 1.4-, 1.7- and 1.85-times the approach velocity in the case of one-side floodplain groyne, and 1.85-, 2.5-, 3-times the approach velocity in the case of groyne at both sides. This happened for $L_{r}=0.5,0.75$ and 1 respectively. The velocity $U$ decreased near the water surface (Figs. 11 and 12).

The impermeable groyne with $L_{r}=1.0$ caused a strong increase of the longitudinal velocity at VP with a strong gradient (Fig. 13(a)). The eddy zone and the vortex generated downstream of the groyne field did not allow a fully developed vertical profile; this result is in agreement with the results of Ahmed et al. (2010) and Uijttewaal (2005). The gradient of the longitudinal velocity in 
the VP became smaller for low value of $L_{r}$. Values of $\left(U / U_{o}\right)_{\max }$ were $1.45,1.65$, and 1.85 for $L_{r}=$ $0.5,0.75$ and 1 , respectively.

The permeable groyne effect on the main channel flow was limited compared with the impermeable one (Fig. 13). Most of the changes in the flow were found around the groynes on the floodplain and the velocity distribution was rather uniform over the entire flow depth. Uijttewaal (2005) found that the permeable groynes that were extended into the main channel, where the effect of the piles was present over the entire water depth, gave uniform vertical profile of velocity $U$. The maximum relative velocity in the vertical plane was dependent on the permeability of the floodplain groynes for all values of $L_{r}$ and could be estimated as averaged values as $1.35,1.25$, and 1.2 for groyne with permeability $P=0.40,0.60$, and 0.80 , respectively.

\subsubsection{Tip velocity}

The tip velocity is the flow velocity measured away from the groyne tip by approximately 5 $\mathrm{mm}$. The flow at the groyne tip had been steeply directed to the main channel increasing its velocity downstream of the groyne in both the HP and VP. The increase of the velocity at the VP occurred near the channel bed helping in generating intensive vortices that lead to a local scour. The analysis focused on the influences of both $L_{r}$ and $P$ on the relative tip velocity $U_{\text {tip }}$ and deflection angle $\theta$ (tip velocity is the resultant flow velocity $(\mathrm{U}, \mathrm{V})$ measured at the nearest point to the groyne tip at the horizontal plane (HP) and deflection angle is the resultant flow velocity angle to $\mathrm{x}$ axis in clockwise direction). Fig. 14(a) presents a comparison between the present results with those of Kang et al. (2011) and Yeo et al. (2005). In the cases of groynes with relative length (relative to the channel total width) equal to $0.375,0.25$ and 0.2 , the measured relative tip velocity decreased from 1.6 to 1.1 as the groyne permeability increased from 0 to $80 \%$. In the case 
of floodplain impermeable groyne with the relative length to the total width of the one floodplain compound channel of 0.5 , the relative tip velocity increased up to 1.78 . The floodplain flow was deviated and combined with the main channel flow resulting in maximizing the tip velocity. The relative tip velocity has varied inversely with the groyne permeability. Empirical equations were suggested to describe the relationship between the relative tip velocity and the permeability of the floodplain groyne (Table 3).

Figure 14(b) shows a comparison of the present measured data with the results of Kang et al. (2011); Wallingford (1997) and Yeo et al. (2005). The results of the permeable groyne coincided with the formula suggested by Yeo et al. (2005) within the range of $0.02<\mathrm{A}^{*}<0.35$, where the area ratio $A^{*}=A_{g} /\left(A_{c}-A_{g}\right), A_{g}$ is the groyne's project area and $A_{c}$ is the cross sectional area of the flow (Table 3).

The relationship between the measured values of the deflection angle $(\theta)$ of the tip velocity in this study, Kang et al. (2011) and Yeo et al. (2005) indicated that, the groyne permeability inversely affected the tip velocity deflection angle (Fig. 14(c) and Table 3).

\subsection{Water surface profiles around the groyne field}

The measurements of the changes of the flow water depth $($ where; $\%$ change $=(($ depth with groyne - depth without groyne)/ depth without groyne) x 100) in the longitudinal direction at the floodplains and main channel are shown in Figs (15-17). The flow, which was totally or partially obstructed by the groyne projection area, caused water surface fluctuations in the groyne field and a rise in the water level upstream of the groyne. Also, a heading up and pressure difference between the upstream and downstream sides of the groyne were observed (Figs11-17). This results from the floodplain groyne installations. In the upstream side of the groyne, as $L_{r}$ increased 
the water depth in the floodplain increased and the location of the highest point of the water surface moved towards the groyne inner edge. In the downstream side of the groyne, the water surface was significantly decreased as a result of increasing $L_{r}$. The greatest value of the water rise and reduction occurred just upstream and downstream of the groyne at relative distance $X_{r}$ from -0.25 to +0.20 . In the case of impermeable groyne on one side of the compound channel with one or two floodplains, the maximum rise in the upstream water depth was estimated as 8 , 4.5 and $3.5 \%$ for $L_{r}=1.0,0.75$ and 0.5 , respectively. This happened for all widths of floodplain. The influence of the permeable groyne on the water depth was greater at the floodplain upstream and downstream of the groyne than at the main channel. The water depth was slightly affected by the permeability. Thus, for permeable groyne with $P=60 \%$, the changes of floodplain water depth was only about $2.5,2$, and $1.5 \%$ for $L_{r}=1.0,0.75$, and 0.5 , respectively. For all values of permeability and $L_{r}$, the change of water depth downstream of the groyne had a mean value of about $-4.5 \%$.

\section{Conclusions}

The present study was conducted to determine how much the physical dimensions and permeability of floodplain groyne influence the flow field using single groyne installed in compound channel floodplains. The findings can be of use to river system with respect to ecology, floodplain and banks protection, and bed scour prevention. The main conclusions that can be drawn are:

(1) Using impermeable groyne in rivers with large single or two floodplains generates a massive flow eddy and separation zones downstream of the groyne and at the upper region of the main channel. The velocity in the main channel near the surface decreases, while it increases in 
the middle and lower regions. In the case of floodplain with impermeable groyne in one side of compound channel with two floodplains, both the other floodplain flow velocity and the groyne tip velocity increase. The velocity changes downstream of the groynes- may lead to floodplain bed and banks erosion, while a degradation in the main channel bed can occur due to the acceleration in its flow velocities. To mitigate those effects, the floodplain impermeable groyne length should be less than half of the floodplain width.

(2) For floodplain single groyne regardless of its permeability and length, its great influences on the flow patterns occur in region located from 2 times the groyne length upstream the groyne to 14 times the groyne length in the downstream side; beyond this range, the flow was slightly affected.

(3) In the case of floodplain single impermeable groyne on one side of symmetrical compound channel, when $L_{r}=0.5,0.75$ and 1.0, negative velocities were generated and reached to $-20,-30$ and $-55 \%$ of the original approach velocity. Those negative velocities are substituted by increasing the flow velocity on the main channel and the opposite floodplain. The increase reaches 1.4-, 1.6-, and 1.85-times the original velocity in the main channel and to 1.75-, 2.25-, 2.75-times the original ones in the opposite floodplain; respectively.

(4) For the floodplain permeable groynes ( $\mathrm{P}=40,60$ and $80 \%)$, the groyne relative length slightly affects the flow compared with the impermeable ones and the great effect is only due to the permeability. The permeability inversely affects the maximum and tip velocities, whiles the minimum and bank velocities increased by increasing it.

(5) For floodplain permeable groyne, the water depth varies just upstream and downstream of the groyne while it was slightly affected at the main channel centerline. In the case of 
impermeable groyne, the water surface (depth) is greatly affected. This effect extends more in the

upstream side of groynes (backwater effects) while it can be weakened shortly downstream of

groyne within a distance of 12-14 times the groyne length.

\section{Acknowledgements}

The authors would like to thank the staff of the hydraulics and irrigation laboratory of Assiut University, Egypt for their support in performing the experimental work. We thank the editor and the anonymous reviewers for their valuable comments that helped improve this manuscript.

\section{References}

Ahmed, H. S., Hasan, M. M., Tanaka, N., 2010. Analysis of flow around impermeable groynes on one side of symmetrical compound channel: An experimental study. Water Science and Engineering, 3(1), 56-66.

Ahmed, H., Tanaka, N., Tamai, N. 2011. Flow modeling and analysis of compound channel in river network with complex floodplains and groynes. Journal of Hydro-Informatics, 13(3), 474-488.

Ahmed, A. A., 2011. Design of hydraulic structures considering different sheetpile configurations and flow through canal banks. Computers and Geotechnics, 38, 559-565.

Ahmed, A. A., 2013. Stochastic analysis of seepage under hydraulic structures resting on anisotropic heterogeneous soils. ASCE Journal of Geotechnical and Geoenvironmental Engineering, 139(6), 1001-1004.

Alauddin, M., Tashiro, T., Tsujimoto, T., 2011. Design of groynes modified with both alignment and permeability for lowland river problems. Annul. Journal of Hydraulic Engineering, JSCE, 67(2), I: 645-652.

Ali, A. N., Mohamed, A. A., 1991. Computation of flow capacity in compound channel with varying roughness. Engineering Research Bulletin, Helwan Univ., 3, 138-153.

Ali, A. N, Mohamed, A. A., AboZeid, G., Mohamed, W. E., 2007. Flow characteristics in compound open channels with one floodplain. Journal of Engineering Sciences, JES, Assiut University, Egypt, 35(4), 909-931.

Alvarez, J. A. M., 1989. Design of groins and spur dikes. Proc. National Conf. Hydraulic Engineering, New Orleans, USA, 296-301.

Baba, Y., Camenen, B., Peltier, Y., Thollet, F., Zhang, H., 2010. Flows and bed load dynamics around spur dyke in a compound channel. $11^{\text {th }}$ Int. Symp. River Sedimentation (ISRS), Stellenbosch, South Africa.

Constantinescu, S. G., Sukhodolov, A., McCoy, A., 2009. Mass exchange in a shallow channel flow with a series of groynes: LES study and comparison with laboratory and field experiments. Journal of Environmental Fluid Mechanics, 9, 587-615.

Ettema, R., Muste, M., 2004. Scale effects in flume experiments on flow around a spur dike in flatbed channel. Journal of Hydraulic Engineering, ASCE, 130(7), 635-646.

Francis, J. R. D., Pattanick, A. B., Wearne, S. H., 1968. Observations of flow patterns around some simplified groyne structures in channels. Proc. Institution of Civil Engineers, 829-846. London. [doi:10.1680/iicep.1968.7821]

Fukuoka, S., Watanaba, A., Kawaguchi, H., Yasutake, Y., 2000. A study of permeable groins in series installed in a straight channel. Ann. Journal of Hydraulic Engineering, JSCE, 44, 1047-1052.

Gu, Z., Ikeda, S., 2008. Experimental study of open channel flow with groins. Proc. $16^{\text {th }}$ IAHR-APD Congress and $3^{\text {rd }}$ Symposium of IAHR-ISHS, Nanjing, China, 1951-1956.

Gu, Z., Akahori, R., Ikeda, S., 2011. Study on the transport of suspended sediment in an open channel flow with permeable spur dikes. Int. Journal of Sediment Research, 26(1), 96-111.

Jong, J., Tominaga, A., 2008. Flow structure and sediment transport around groynes in compound 
open channels. $8^{\text {th }}$ Int. Conf. Hydro-Science and Engineering, Nagoya University, Nagoya, Japan, 659-666.

Kang, J., Yeo, H., Kim, S., Ji, U., 2011. Permeability effects of single groin on flow characteristics. Journal of Hydraulic Research, 49(6), 728-735.

Koken M., 2011. Coherent structures around isolated spur dike at various approach flow angles. Journal of Hydraulic Research, 49(6), 736-743.

Koken M., Constantinescu, S. G., 2008. An Investigation of the flow and scour mechanisms around isolated spur dikes in a shallow open channel 1: Conditions corresponding to the initiation of the erosion and deposition process. Journal of Water Resources Research, 44, W08406. [doi: 10.1029/2007WR006489].

Liu, J., Tominaga, A., Nagao, M., 1994. Numerical simulation of the flow around the spur dikes with certain configuration and angles with bank. Journal of Hydro-Science and Engineering, 12(2), 85-100.

McCoy, A., Constantinescu, G., Weber, L., 2006a. Exchange processes in a channel with tow emerged groynes. Journal of Flow, Turbulence, Combustion, 77, 97-126.

McCoy, A., Constantinescu, G., Weber, L., 2006b. Large eddy simulation of flow in a channel with multiple lateral groyne fields. $7^{\text {th }}$ Int. Conf. Hydro-Science and Engineering, ICHE, Philadelphia, USA.

McCoy, A., Constantinescu, G., Weber, L., 2007. A numerical investigation of coherent structures and mass exchange process in channel flow with two lateral submerged groynes. Water Resources Research, American Geophysical Union, (43), W05445.

McCoy, A., Constantinescu, G., Weber, L., 2008. Numerical investigation of flow hydrodynamics in a channel with a series of groynes. Journal of Hydraulic Engineering, ACSE, 134(2), 157-172.

Mojtaba, G. K. Abbas, B. G., 2009. Effect of groynes opening percentage on river outer bank protection. Journal of Applied Sciences, 9(12), 2325-2329.

Muraoka, H., Fushimi, T., Kadota, A., Suzuki, K., 2008. Experimental study on changes of bed configuration caused by permeable groyne of stone gabion. Proc. $16^{\text {th }}$ IAHR-APD Congress and $3^{\text {rd }}$ Symposium of IAHR-ISHS, Nanjing, China, 1072-1077.

Peltier, Y., Proust, S., Rivière, N., Paquier, A., Thollet, F., 2009. Measurement of momentum transfer caused by a groyne in a compound channel. $33^{\text {rd }}$ IAHR Biennial Congress, Vancouver, CAN.

Prooijen, B. C., Battjes, J. A., Uijttewaal, W. S. J., 2005. Momentum Exchange in Straight Uniform Compound Channel Flow. Journal of Hydraulic Engineering, ACSE, 131(3), 175-183.

Soliman, M. M., Attia, K. M., Kotb, Talaat, A. M., Ahmad, A. F., 1997. Spur dike effects on the river Nile morphology after High Aswan Dam. Proc. $27^{\text {th }}$ IAHR Congress, Managing Water, A, 805-810.

Rehbock, T. 1929. Discussion of precise weir measurements. Trans., ASCE, 93, 1143-1162.

Teraguchi, H., Nakagawa, H., Muto, Y., Baba, Y., Zhang, H., 2008. Effects of groins on the flow and bed deformation in non-submerged conditions. Ann. Disas. Prev. Res. Inst., Kyoto Univ., $51 \mathrm{~B}, 625-631$

Tominaga, A., Nezu, I., 1991. Turbulent structure in compound open channel flows. Journal of Hydraulic Engineering, ASCE, 117(1), 21-41.

Tominaga, A., Nagao, M., Nezu, I., 1997. Flow structure and mixing processes around porous and submerged spur dikes. Proc. $27^{\text {th }}$ IAHR congress, San Francisco, California, 251-256.

Uijttewaal, W. S. J., 1999. Groyne field velocity patterns determined with particle tracking velocimetry. Proc. $28^{\text {th }}$ IAHR congress, Graz, Austria.

Uijttewaal, W. S. J., 2005. Effects of groyne layout on the flow in groyne fields: Laboratory experiments. Journal of Hydraulic Engineering, ASCE, 131(9), 782-791.

Uijttewaal, W. S. J., Lehmann, D., Van Msazijk, A., 2001. Exchange processes between a river and its groyne fields: model experiments. Journal of Hydraulic Engineering, ASCE, 127(11), 928-936.

Weitbrecht, V., Socolofsky, S. A., Jirka, G. H., 2008. Experiments on mass exchange between groin fields and the main stream in rivers. Journal of Hydraulic Engineering, ASCE 134(2), 173-183.

Yeo, H. K., Kang, J. G., Kim, S. J., 2005. An Experimental study on tip velocity and downstream recirculation zone of single groynes of permeability change. KSCE, Civil Engineering, 9(1), 

29-38.

466 


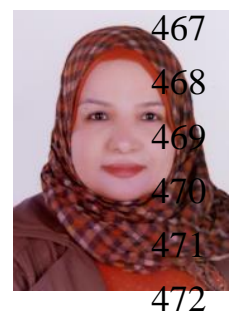

Mona Mostafa is an assistant professor of water resources and river engineering at Faculty of Engineering, South Valley University, Egypt, and Visiting Researcher at Nagoya Institute of Technology, Japan. She received the B.Sc. and M.Sc. in Civil engineering (Hydraulics) from Faculty of Engineering, Assiut University, Egypt, in 2000\&2005, and the Ph.D. in River Engineering from South Valley University, Egypt, in 2013. Her research and publication interests include Hydraulics, River

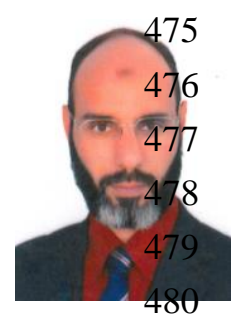

Hassan Ahmed is an assistant professor of water resources and river engineering at Faculty of Engineering, South Valley University, Egypt, and Faculty of Engineering at Rabigh, King Abdul-Aziz University, KSA. He received the B.Sc. and M.Sc. in Civil engineering (Hydraulics) from Faculty of Engineering, Assiut University, Egypt, in 1996\&2000, and the Ph.D. in Water Resources Management from Graduate School of Science and Engineering, Saitama University, Japan, in 2009. He is a member of the International Association for Hydro-Environment Engineering and Research (IAHR). His research and publication interests include Water Resources Management, River Engineering and Management, Sediment and Erosion Analysis.

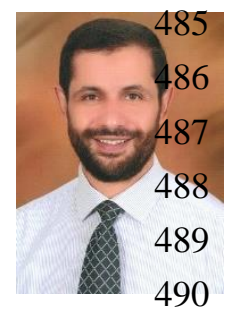

Ashraf Ahmed is a Senior Lecturer in Flood and Coastal Engineering at Brunel University London, UK. His areas of expertise include the design of hydraulic structures, saltwater intrusion in coastal aquifers, stochastic modelling of heterogeneous geologic formations, and the groundwater flow and mass transport in hydrogeological systems. Ashraf published over 55 peer-reviewed articles in international conferences and journals.

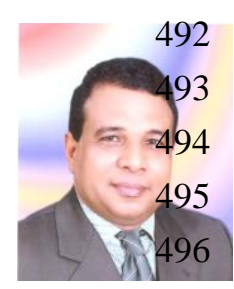

497

Gamal Abdel-Raheem is the professor of water resources and Hydraulics at Faculty of Engineering, Assiut University, Egypt. Now, He is working as Vice dean of learning and student affairs and the respective dean of faculty of Engineering, Assiut University. He received his B. Sc. \& M. Sc. in Civil engineering from Faculty of Engineering, Assiut University, Egypt, in 1984, 1989 (Hydraulics). The Ph.D. was in water resources and hydraulics under Egyptian channel system between Saitama University in Japan and Assiut University in Egypt, 1998. His research and publication interests are in Sediment and Erosion, Soil water interaction pollutants.

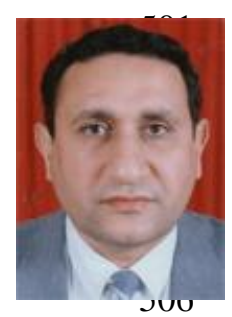

Nashat Ali is the professor of Hydraulics \& water resources and former vice Dean for Community Services and Environmental affairs at Faculty of Engineering, Assiut University, Egypt. He received his B.Sc. \& M.Sc. in Civil Engineering (Hydraulics) from Faculty of Engineering, Assiut University, in 1974\&1978, respectively. His Ph.D. was in hydraulics from Institute of Science and Technology, University of Manchester, UK, in 1986. His research and publication interests include Water Resources, River Engineering, Sediment and Erosion, and Water Supply Networks. He has supervised various M.Sc. \& PhD thesis's and published four educational books in Hydraulics, Hydrology and Hydraulic Structures. 


\section{Experimental study of Flow characteristics around floodplain single groyne}

\section{Figures Captions}

Figure 1 Sketches of flumes, measuring points, and permeable groynes models.

Figure 2 Velocity distribution maps of $U(\mathrm{~cm} / \mathrm{s})$ on HP for single impermeable groyne and double floodplains (Ahmed et al. 2010).

Figure 3 Values of $\left(U / U_{0}\right)_{\max }$ and $\left(U / U_{0}\right)_{\min }$ on the horizontal plane HP for single impermeable groyne and double floodplains (Ahmed et al. 2010).

Figure 4 Symmetrical single groynes arranged in one-line in both floodplains.

Figure 5 Single impermeable groynes in one floodplain compound channel.

Figure 6 Velocity distribution maps of the flow longitudinal velocity $U$ at HP for single permeable groyne and single floodplain.

Figure 7 Values of $\left(U / U_{o}\right)_{\max }$ and $\left(U / U_{o}\right)_{\min }$ in the horizontal plane (HP) for single permeable groyne and single floodplain.

Figure 8 The lateral velocity $(V)$ distribution at HP for single permeable groyne and single floodplain $(P=40 \%)$.

Figure 9 Vertical velocity $(W)$ distribution in VP for single permeable groyne and single floodplain $\left(L_{r}=1.0\right)$.

Figure 10 Single groyne and single floodplain, the relationship between the groyne permeability and the ultimate values of the longitudinal relative maximum and minimum velocities.

Figure 11 Velocity profiles and flow maximum relative longitudinal velocity $U$ at VP for single impermeable groyne and double floodplains.

Figure 12 Velocity profiles and maximum relative longitudinal flow velocity at VP for one-line two symmetrical impermeable groynes and double floodplains.

Figure 13 Maximum relative longitudinal velocity at VP for single floodplain and single groyne.

Figure 14 Variation of the Tip velocity.

Figure 15 Changes of water depth at the floodplains and main channel centerlines for single impermeable groyne and double floodplains.

Figure 16 Changes of water depth at the floodplains and main channel centerlines for single impermeable groyne and single floodplain. 
Figure 17 Changes of water depth across the lateral section of the flume for Single groyne and single floodplain. 

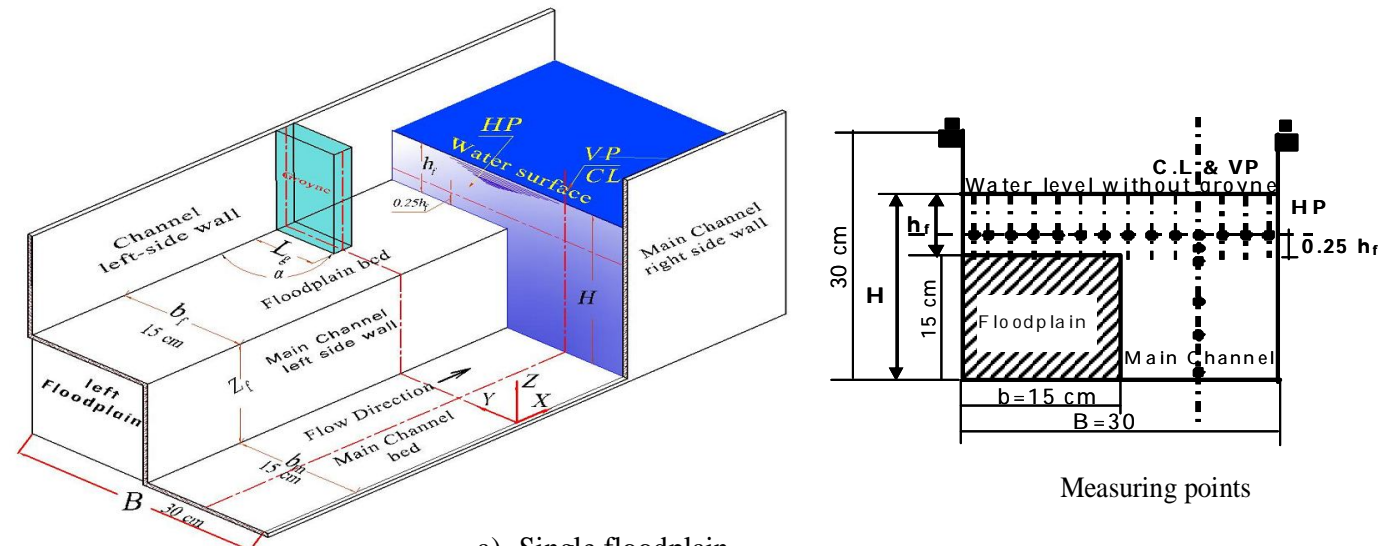

a)- Single floodplain.

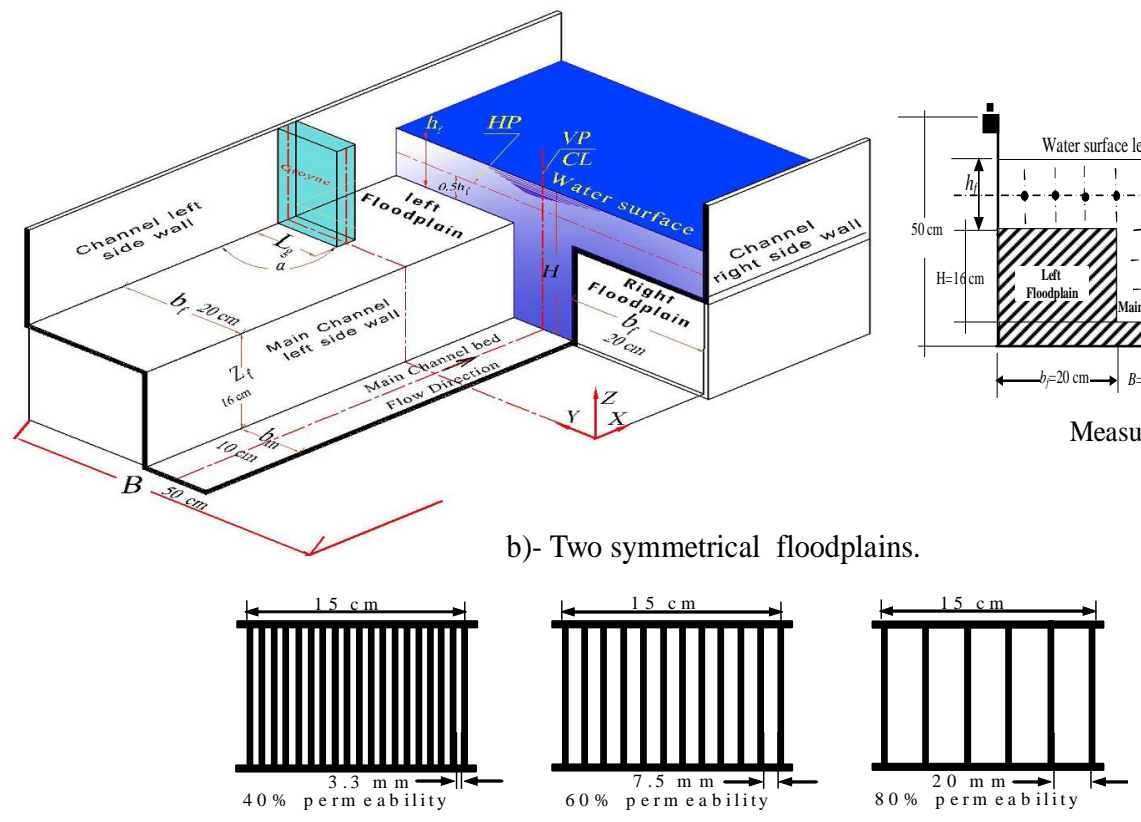

c)- Permeable Groyne models

Figure 1 


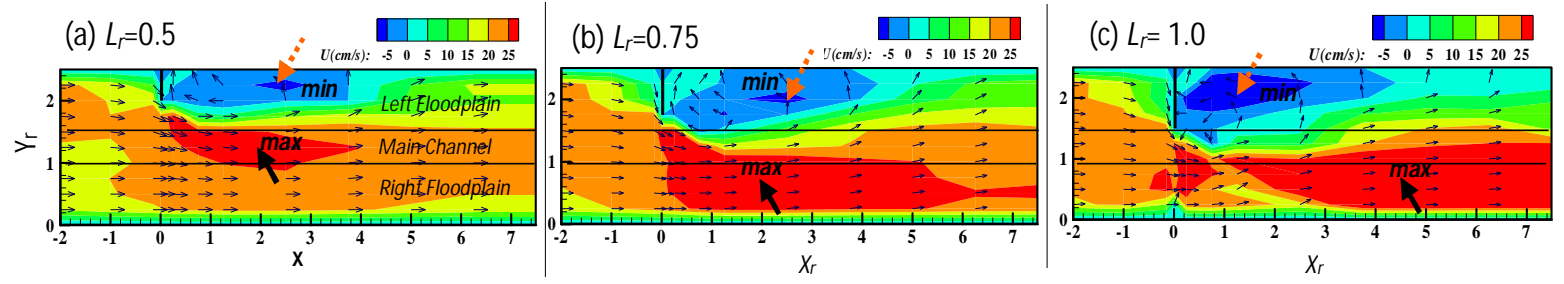

Figure 2 

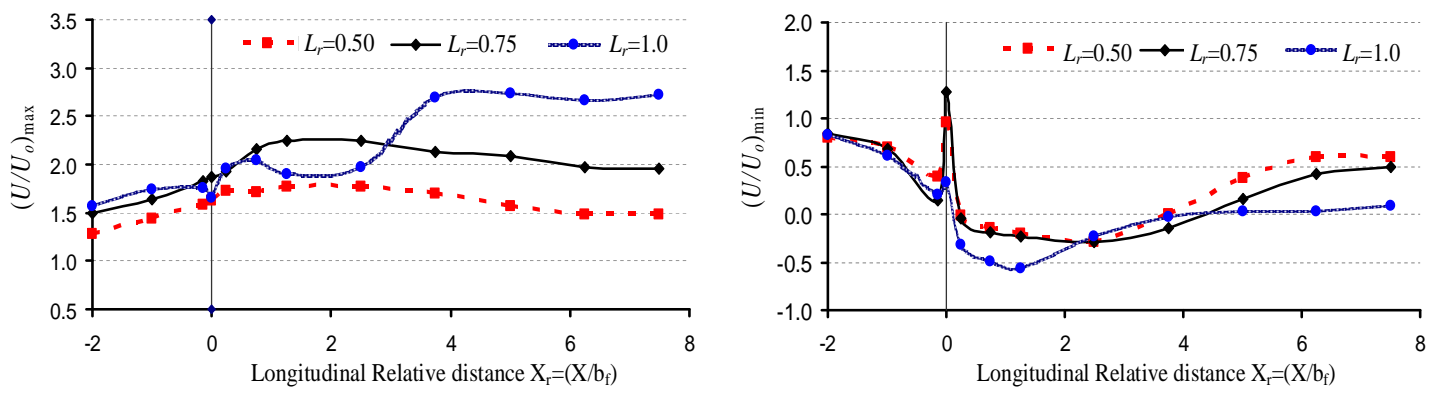

Figure 3 

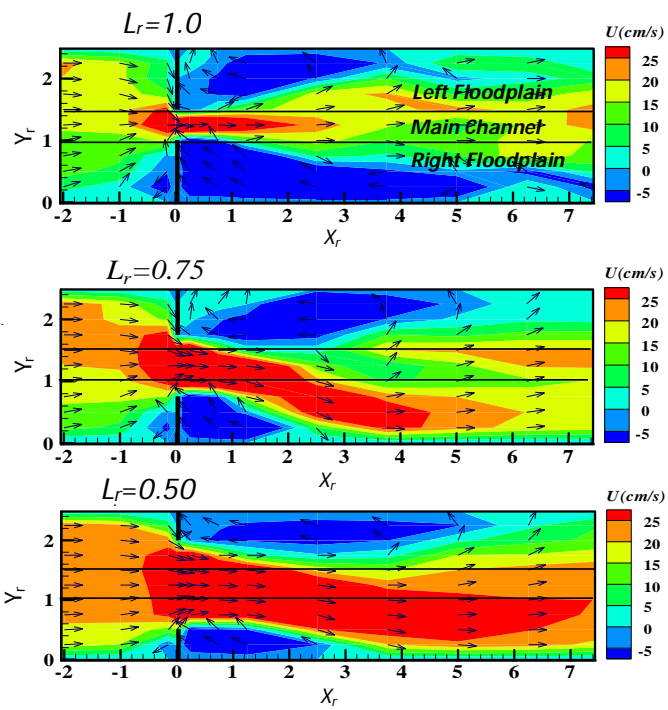

(a) Distribution map of the flow longitudinal velocity U at HP
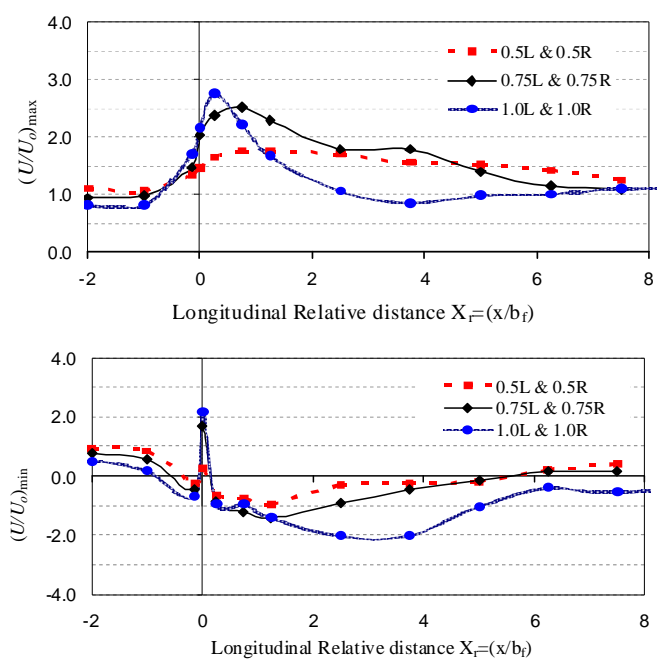

(b) Values of the flow maximum and minimum longitudinal velocity relative to the approach velocity at HP

Figure 4 

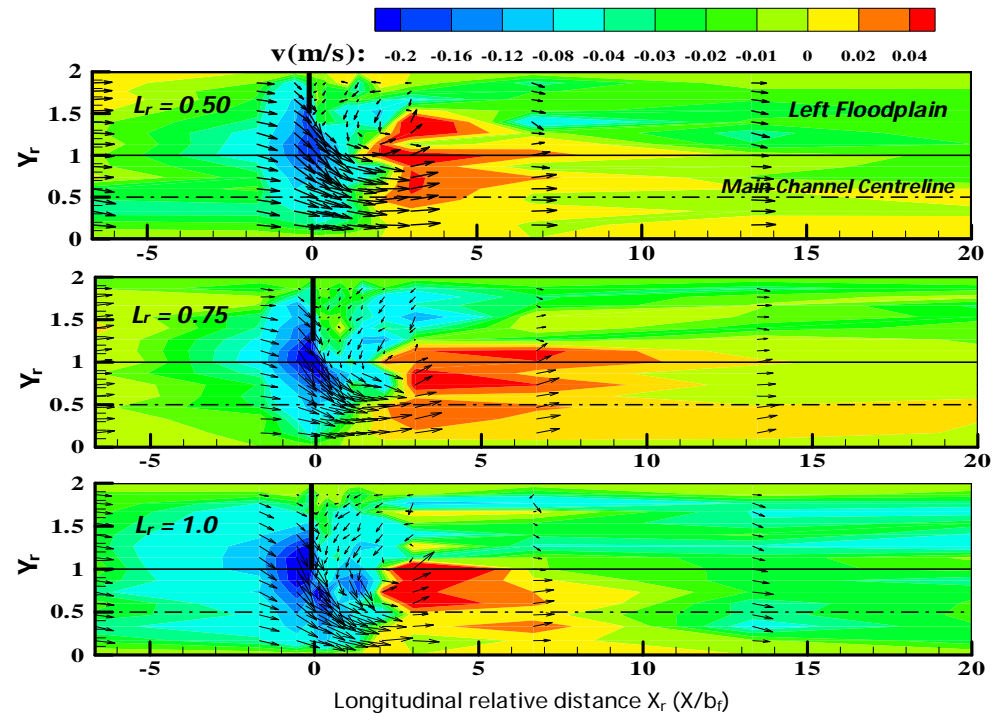

(b) Velocity distribution maps of the flow lateral velocity $(\mathrm{V})$ at $\mathrm{HP}$

Figure 5 

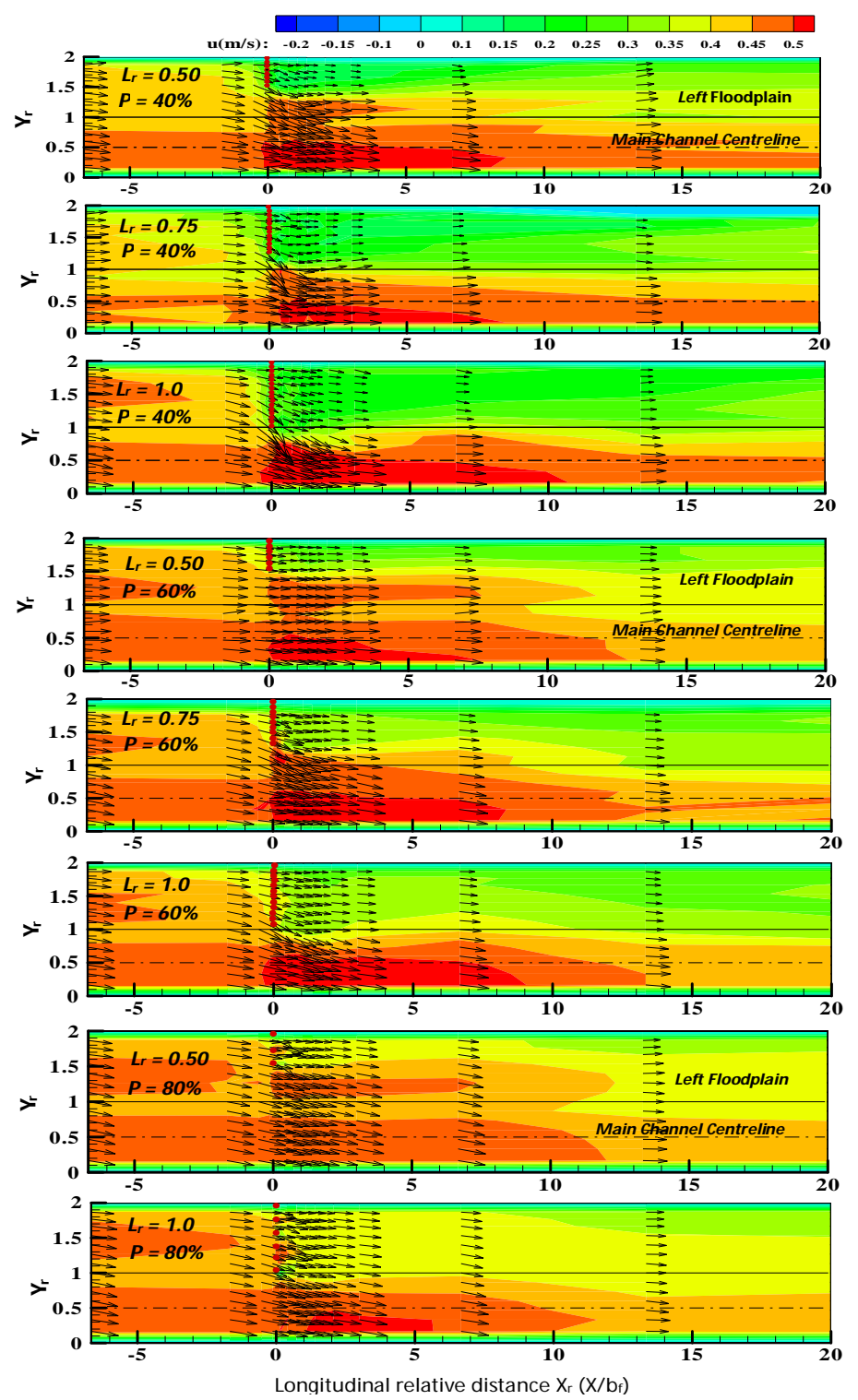

Figure 6 

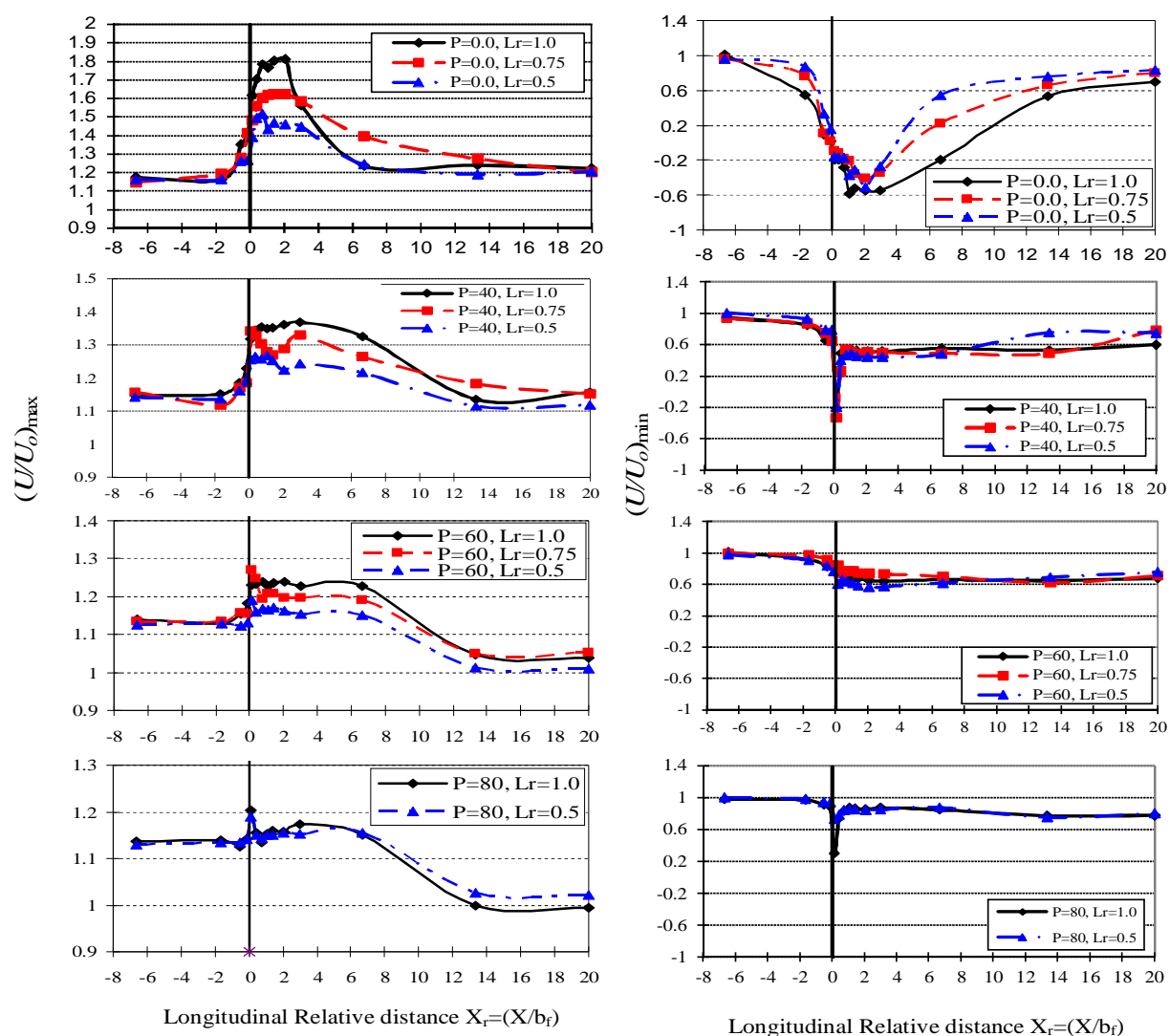
a)- $\left(U / U_{o}\right)_{\max }$

$$
\text { b)- }\left(U / U_{0}\right)_{\text {min }}
$$

Figure 7 

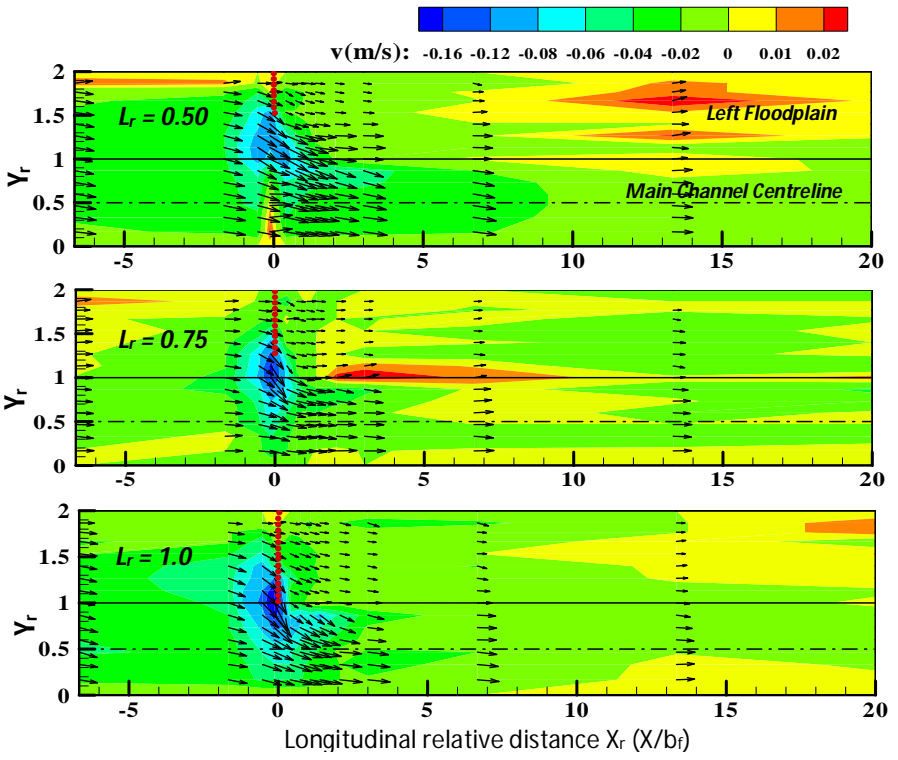

Figure 8 


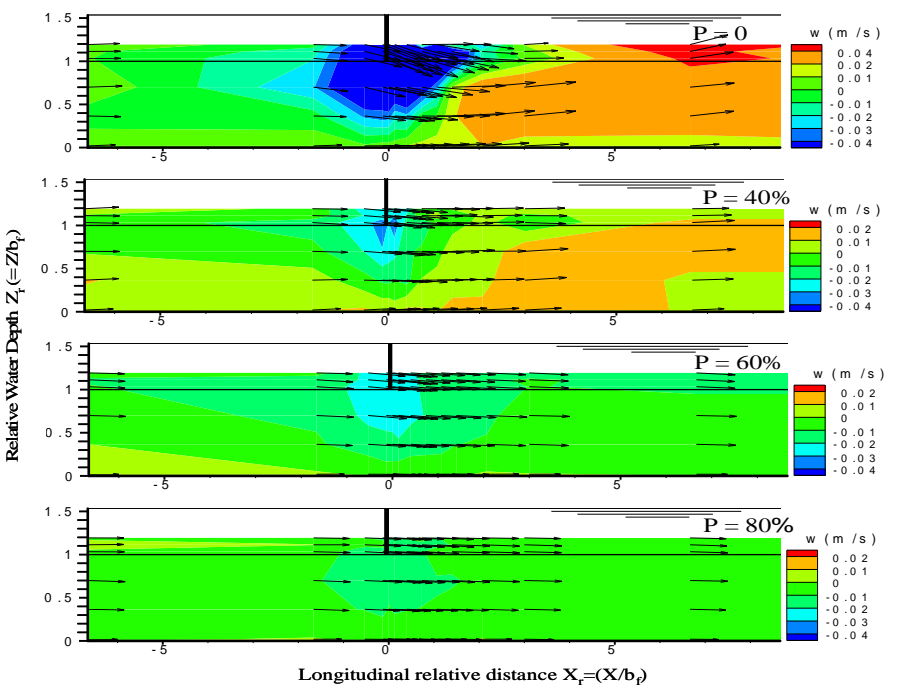

Figure 9 


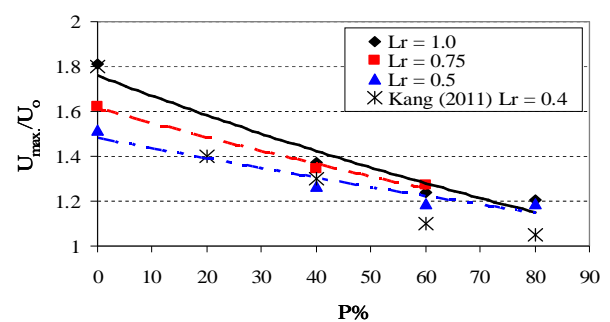

(a) The ultimate values of the longitudinal relative maximum velocities

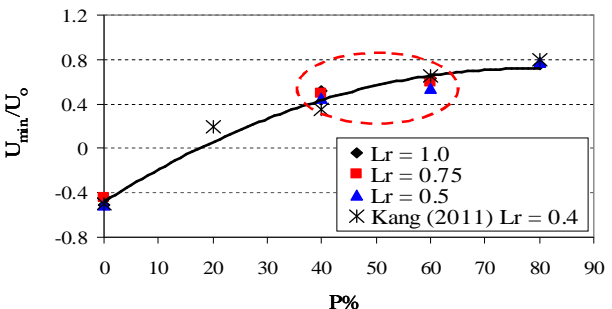

(b) The ultimate values of the longitudinal relative minimum velocities

Figure 10 

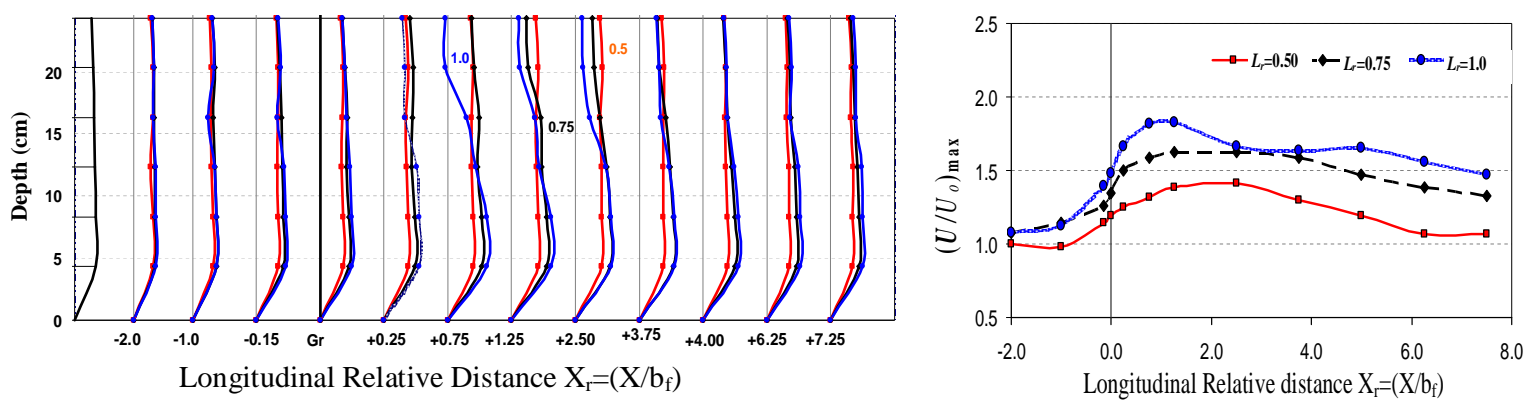

Figure 11 

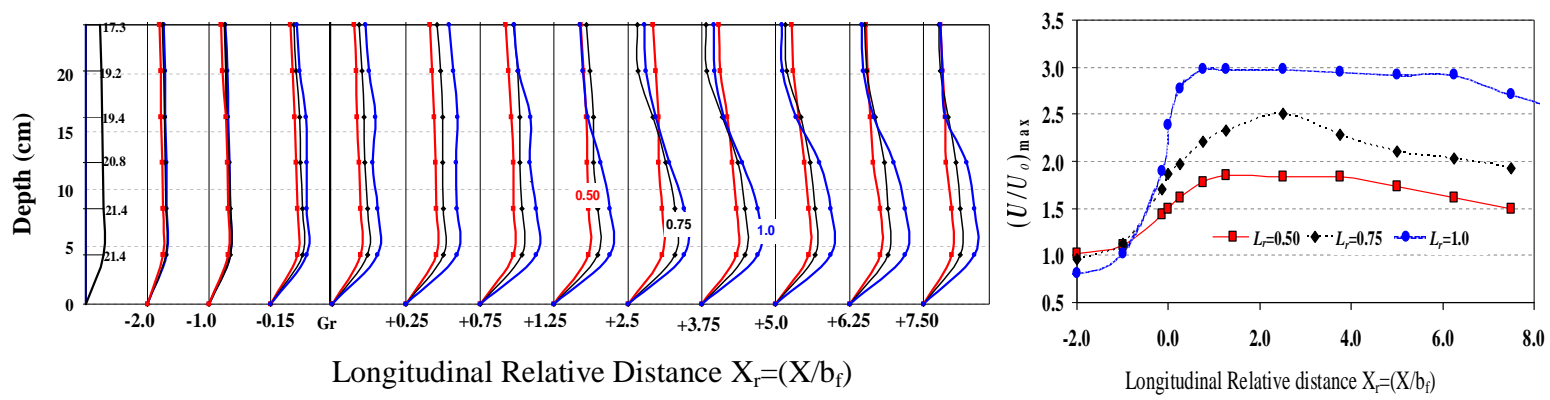

Figure 12 


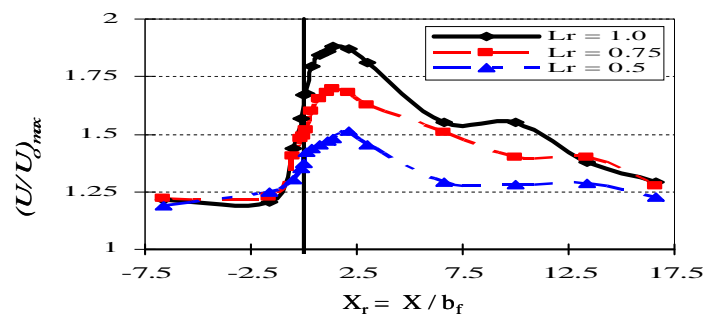

(a) Impermeable groyne

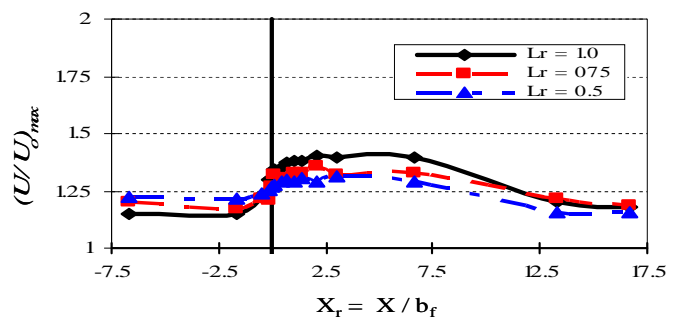

(b) Permeable groyne with $\mathrm{P}=40 \%$

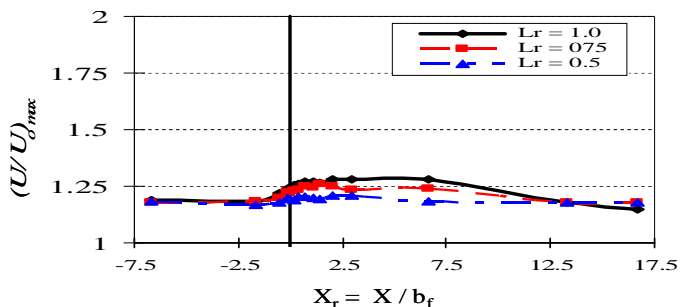

(c) Permeable groyne with $\mathrm{P}=60 \%$

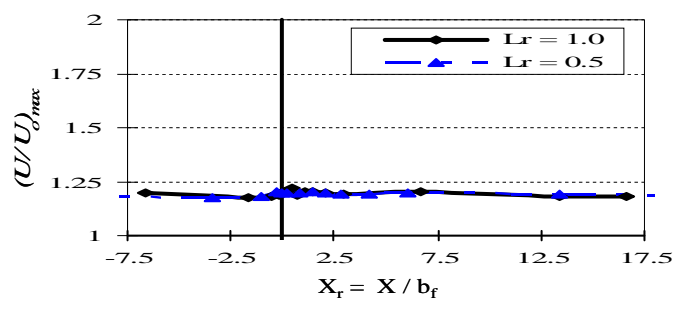

(d) Permeable groyne with $\mathrm{P}=80 \%$

Figure 13 


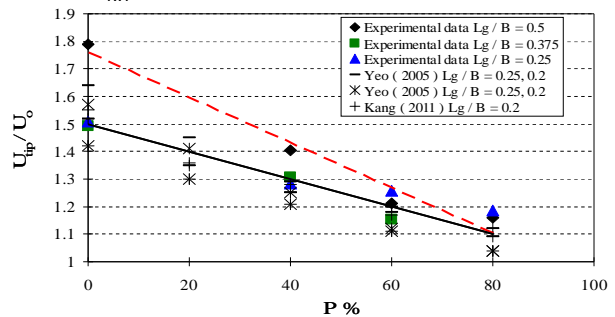

(a) Relation between the relative tip velocity and permeability

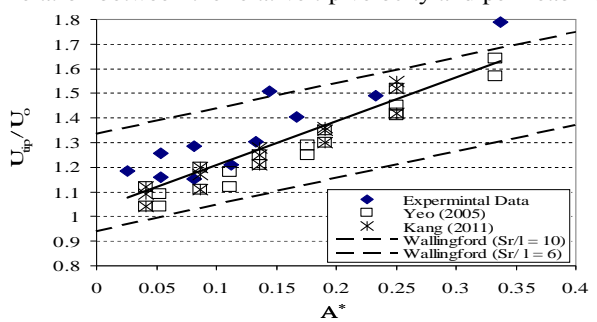

(b) Relation between the relative tip velocity and area ratio

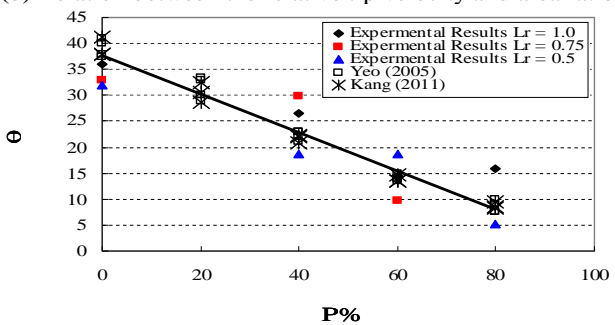

(c) Relation between flow separation angle $(\theta)$ and groyne permeability $P$

Figure 14 


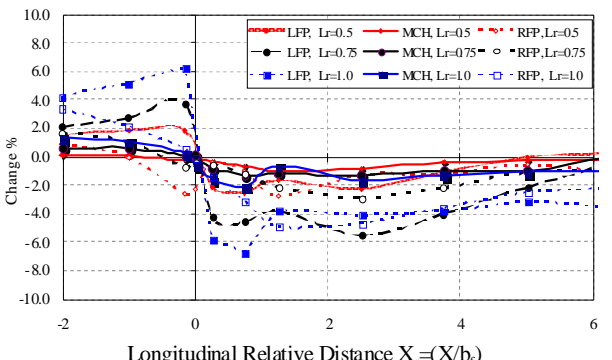

(a) Single groyne on the left side floodplain (LFP)

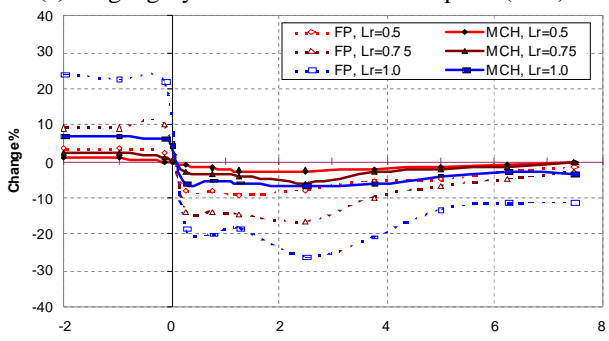

Long itudinal Relative distance $\mathrm{X}_{\mathrm{r}}=\left(\mathrm{X} / \mathrm{b}_{\mathrm{f}}\right)$

(b) Symmetrical single groyne on both floodplains (in one-line).

Figure 15 


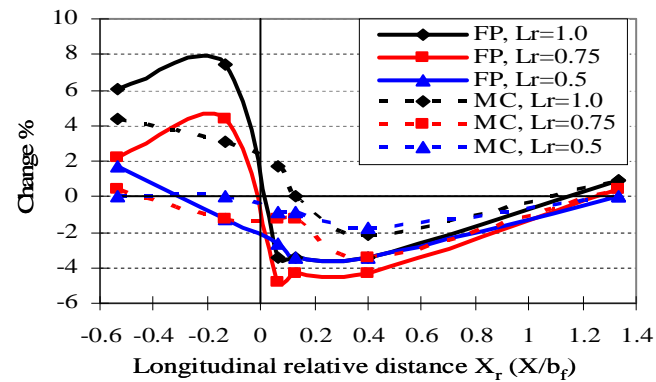

(a) Impermeable groynes

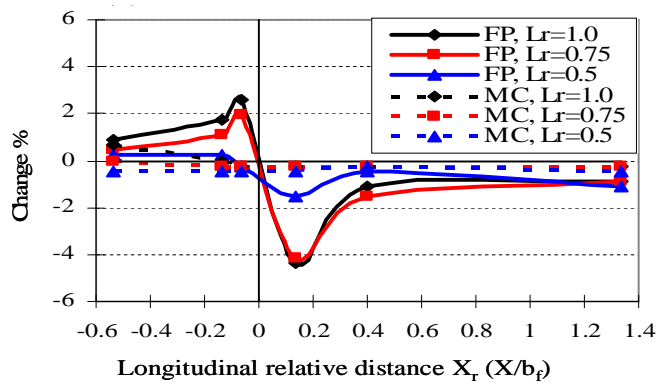

(b) Permeable groynes ( $\mathrm{P}=60 \%)$

Figure 16 


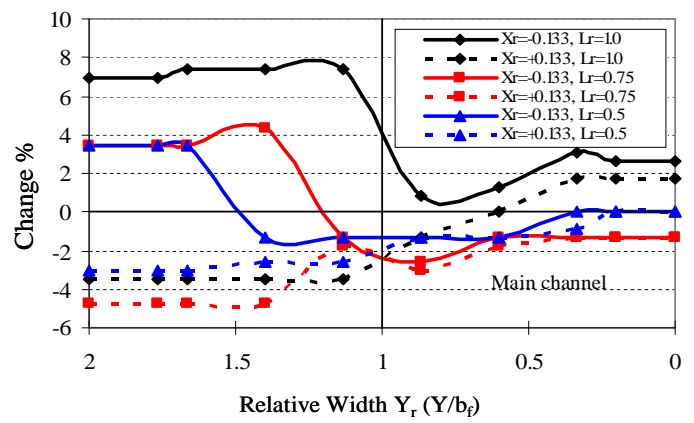

(a) Impermeable groynes

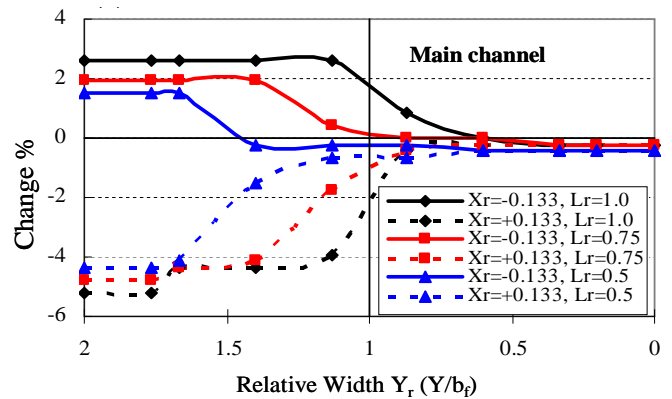

(b) Permeable groynes ( $\mathrm{P}=60 \%)$

Figure 17 